\title{
Gabriel Weston: The different time zones of doctors and patients
}

\author{
Gabriel Weston ENT surgeon
}

Surrey

I accompanied a friend to dialysis this week. She's gone on alternate days for the past 20 years, while, in all my years as a doctor, I'd never been to one of these centres.

It ran like clockwork. My friend was allocated a bed and weighed. Numbers were punched into the machine directing four litres to be drawn off at a rate of $380 \mathrm{~mL} / \mathrm{min}$, a bag of dialysis fluid was popped in, and her neck line was hooked up. Within moments of her arriving, a pie chart on the monitor showed that the first fraction of her four hour session had elapsed. Swaddled in a jumper, scarf, and blanket, she didn't feel much like talking. So, after fidgeting a while, I resolved to stop checking the screen every few minutes and fell instead to thinking about time.

Aristotle and Newton said that time is universal, a dimension that exists outside of us, steadily present, whether we perceive it or not. Our Western model of healthcare provision, with its emphasis on calendar and clock time, owes plenty to this position.

It's harder to see how Einstein makes himself felt in everyday clinical life, but he certainly revolutionised our understanding of time, proving with his theory of relativity that it isn't universal after all but differs between objects, depending on their frame of reference. Two identical synchronised clocks, one on top of Everest and one at sea level, will diverge by about 30 microseconds a year.

We doctors enjoy a temporal freedom that has completely disappeared for many of our patients

But phenomenology, in its clear distinction between objective and subjective time, is the school of philosophy that speaks to me most. Havi Carel, a brilliant thinker who also-relevantly—has chronic lung disease, ${ }^{1}$ explains it like this: "The world of the ill is different in many ways to the world of the healthy. Its space and time are different."

S Kay Toombs, another philosopher-patient, adds that the objective dimension of clock time is the one in which doctors operate but that its rhythm is often out of sync with the altogether more subjective time signature of a patient's illness. If only we could tackle the "incommensurability" between these two time zones, she argues, we would solve many problems of doctor-patient communication. ${ }^{3}$

We doctors feel battered by our schedules, but, in health, we still enjoy a temporal freedom that has completely disappeared for many of our patients. In any week that my friend receives 12 hours of haemodialysis, my kidneys do their 168 hours of work silently. While I sit near the humming dialysis machine hatching plans, I see how her past and future have collapsed into a present that is defined by the demands of her disease.

I bide my time quietly until the four hours are up. But, after I drop my friend home, I hit the motorway hard, pressing the accelerator, as the sun reaches the height of its compass in the sky.

Competing interests: I have read and understood BMJ policy on declaration of interests and declare that I have no competing interests.

Provenance and peer review: Commissioned; not externally peer reviewed.

1 Carel H, Johnson S, Gamble L. Living with lymphangioleiomyomatosis. $B M$ 2010;340:c848. 10.1136/bmj.c848 20228149

2 Carel H. Phenomenology of illness. Oxford University Press,

201610.1093/acprof:oso/9780199669653.001.0001.

Toombs SK. The temporality of illness: four levels of experience. Theor Med 1990;11:227-41. 10.1007/BF00489832 2247858

Published by the BMJ Publishing Group Limited. For permission to use (where not already granted under a licence) please go to http://group.bmj.com/group/rights-licensing/ permissions 